\title{
Analysis and implementation of a delay-compensated deadbeat current controller for solar inverters
}

\author{
G.-K.Hung, C.-C.Chang and C.-L.Chen
}

\begin{abstract}
The delay problem of a deadbeat current controller for solar inverters is investigated. By applying the $z$-transformation technique, it is found that system stability is degraded because of the delay of one-sampling-period due to the nonzero computational time of the microprocessor and the conversion time of $\mathrm{A} / \mathrm{D}$ converters. The frequency response of the system loop gain also indicates that the inverter output current oscillates at one sixth of the sampling frequency. Through the analysis presented, it is shown that the predictive current observer based controller compensates this time delay, while remaining an accurate current controller for solar inverters. Computer simulations are performed, and a $1 \mathrm{~kW}$ solar inverter prototype is constructed to verify the analytical results.
\end{abstract}

\section{Introduction}

Deadbeat current control [1] is widely used in PWM $\mathrm{DC}-\mathrm{AC}$ voltage source inverters or $\mathrm{AC}-\mathrm{DC}$ converters for its fast response and high accuracy. Based on regular sampling of load variables, the controlled current is forced to keep up with the reference at the end of each sampling period. For example, in motor drive applications [2], the inverter output current is regulated by adjusting the widths of its pulsed output voltage. The steps to determine the varying pulse widths include sampling the output current and rotor angular velocity, estimating rotor flux, generating reference current and finally making calculations with motor parameters. All should be done at the beginning of each sampling period. Another example is the shunt-type active power filter [3]. The circuit output is connected to the mains. Although the mains voltage is assumed to be ideally sinusoidal without any need of estimation, the current injection profile or the reference current has to be predicted by some rather complicated algorithm because it is of rich harmonics even in the steady state. Then the output current can be controlled in a deadbeat way. A PWM AC-DC converter [4] would be the simplest case. The sinusoidal reference current and the output DC load do not change rapidly. The input current is controlled by applying the basic deadbeat control technique to achieve unity input power factor operation.

Nevertheless, the deadbeat control technique always suffers from a common delay problem in discrete systems. Nonzero computational time of the microprocessor and conversion time of $\mathrm{A} / \mathrm{D}$ converters cause a significant time delay to control signal generation. Research work [5-7] has shown that this time delay degrades system stability to some extent. The problem is severe, especially when low-

\footnotetext{
( IEE, 2001

IEE Proceedings online no. 20010440

DOI: $10.1049 /$ ip-cds:20010440

Paper first received 13th September 2000 and in revised form 29th March 2001 The authors are with the Power Electronics Laboratory, Department of Electrical Engineering, National Taiwan University, Taipei, Taiwan, Republic of
} China speed chips are used. Unfortunately, conventional control methods are difficult to modify for compensation. For example, if one attempts to design the feedback controller on the Laplace plane, the time delay exhibits itself in an exponential form, which in turn forms a nonrational plant transfer function, difficult for compensation. On the other hand, if the whole system is modelled on the z-plane, the frequency response method [8] can be applied by using bilinear transformation, but the validity of this kind of method is limited below a quarter of the sampling frequency. Many efforts have been made to alleviate this problem. A modified version of frequency response method has been proposed [9] based on minimising a weighted mean-square error between the frequency response of a discrete system and that of a continuous one. However, complex computer-aided design is required. To make compensation directly on the z-plane, another method [10] was invented for prediction at the output of the controller. The restriction is that the control signal must be approximated by a piecewise low-degree polynomial. Some methods have also been proposed for the PWM voltage source inverter and for converter applications. The local average value (LAV) current control method [3] solves the problem in a different way. By making samples at half of each sampling period to control the LAV of current, the time delay is avoided. Despite the computational time being extended to about one-half of the sampling period, it is not easy to be sure of the exact sampling instants. Other methods include reducing controller gain [5], using a binomial current controller [11], and adopting a predictive current observer based control algorithm [12]. However, the improvement of stability margins is not clear in applications to solar inverters.

In this paper, the stability problem of a delayed deadbeat current controller for solar inverters is first analysed, both on the $z$-plane and in the frequency domain. Different compensation methods are also investigated in the same way for comparison and to give a comprehensive understanding of their effects on system stability. Through the analysis, it can be shown that the predictive current observer based controller recovers the phase margin of the system delayed by one-sampling-period to that of the nondelayed one, 
while remaining an accurate current controller. Computer simulations are performed and a $1 \mathrm{~kW}$ solar inverter, using an Intel 80196MC microprocessor as the main controller, is implemented to verify the analytical results.

\section{Analysis of delay problem in digital controlled solar inverters}

\subsection{Deadbeat current control of solar inverter}

Fig. 1 shows the common power circuit of a single-phase solar inverter. A boost-type DC-DC voltage regulator forms the first stage to provide a stable DC bus voltage, independent of output variations of the solar panels. The second stage is a full-bridge $\mathrm{DC}-\mathrm{AC}$ inverter with an output $\mathrm{L}-\mathrm{C}$ filter. A solar inverter generally has two operation modes. In the voltage mode, it functions as an ideal voltage source, maintaining a sinusoidal voltage waveform of fixed magnitude and frequency, like an UPS. In current mode, it is connected to the mains. The objective is to generate as much power as possible, so the inverter output current is controlled to operate solar panels at their maximum power point. This is the so-called maximum power point tracking (MPPT) operation. Also, to avoid harmonics pollution, the current reference is defined as a sinusoidal one of unity power factor. This is somewhat like a PWM AC-DC converter except for the opposite power directions. The analysis in this paper will be focused on the current mode operation.

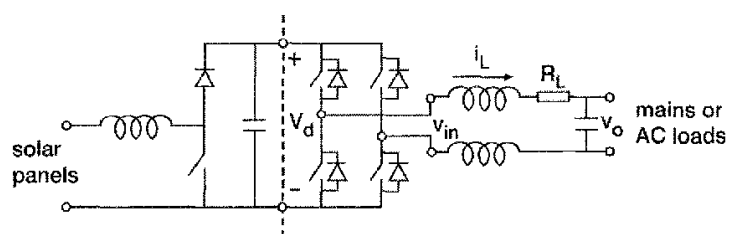

Fig. 1 Power circuit of solar inverter

Referring to Fig. 1, assume that the capacitor current at the inverter output terminals is negligible (e.g. the current of a $3 \mu \mathrm{F}$ capacitor connected to the $110 \mathrm{~V}, 60 \mathrm{~Hz}$ mains is $0.12 \mathrm{~A}$, which is only $1.3 \%$ of $9.09 \mathrm{~A}$ for $1 \mathrm{~kW}$ output power). Thus, it is possible to adjust the inverter output current by controlling the inductor current. The deadbeat current control scheme is developed as follows. First, the inductor equation is discretised as

$$
i_{L}[k+1]=i_{L}[k]+\frac{T_{s}}{L} \cdot\left(\overline{v_{i n v}}[k]-\overline{v_{o}}-R_{L} \cdot \overline{i_{L}}[k]\right)
$$

with

$i_{L}[k]$ : the inductor current measured at the $k$ th sampling instant,

$T_{S}: \quad$ the sampling period of A/D converters,

$L: \quad$ the total inductance of $\mathrm{L}-\mathrm{C}$ filter,

$\hat{v_{\text {in }}}[k]$ : the local average value of inverter output voltage during the $k$ th sampling period,

$\bar{v}_{o}[k]$ : the local average value of the mains voltage during the $k$ th sampling period,

$R_{L}$ : the effective series resistance of filter inductors,

$\overline{i_{L}}[k]$ : the local average value of the inductor current during the $k$ th sampling period.

If the mains voltage is given by

$$
v_{0}(t)=V_{o} \cdot \sin (\omega t)
$$

its local average value (LAV) during the $k$ th sampling period can be estimated as

$$
\begin{aligned}
\tilde{v}_{0} & =\frac{1}{T_{s}} \cdot \int_{k T_{s}}^{(k+1) T_{s}} v_{o}(t) d t \\
& =\frac{V_{o}}{\omega T_{s}} \cdot\left[\cos \left(\omega k T_{s}\right)-\cos \left(\omega(k+1) T_{s}\right)\right]
\end{aligned}
$$

Once $T_{s}, L, \tilde{v}_{o}[k]$ are known with $R_{L} \cdot i_{I}[k]$ being neglected, and $i_{Y}[k]$ is sampled at the $k$ th sampling instant, the LAV of inverter output voltage required to regulate the output current can be synthesised from eqn. 1 by

$$
\begin{aligned}
\overline{v_{i n v}}[k] & =\frac{L}{T_{s}} \cdot\left(i_{r}[k+1]-i_{L}[k]\right)+\tilde{v}_{o}[k] \\
& =u[k]+\tilde{v}_{o}[k]
\end{aligned}
$$

where $i_{f}[k+1]$ is the value of the reference current at the $(k+1)$ th sampling instant, and $u[k]$ represents the controller output signal,

$$
u[k]=\frac{L}{T_{s}} \cdot\left(i_{r}[k+1]-i_{L}[k]\right)
$$

The pulse width of inverter output voltage is easily determined by

$$
D[k]=\frac{\overline{v_{i n v}}[k]}{V_{d}}
$$

where $V_{d}$ is the $\mathrm{DC}$ bus voltage

Substituting eqn. 4 into eqn. 1, it is seen that the inductor current is forced to keep up with its sinusoidal reference at the end of each sampling period, except for the difference caused by possible estimation error of the mains voltage and the voltage drop due to the inductor effective series resistance:

$$
\begin{aligned}
i_{L}[k+1] & =i_{r}[k+1]+\frac{T_{s}}{L} \cdot\left(\tilde{v}_{o}[k]-\overline{v_{o}}[k]-R_{L} \cdot \overline{i_{L}}[k]\right) \\
& =i_{r}[k+1]+\frac{T_{s}}{L} \cdot \Delta v_{o}[k]
\end{aligned}
$$

The current error term $\left(T_{s} / L\right) \cdot \Delta v_{0}[k]$ determines the steady-state performance of a deadbeat controller. To reduce it, some modifications could be made to the control algorithm. For example, the mains voltage estimation formula in eqn. 3 can be replaced by linear extrapolation. This should improve the estimation results in the case where the mains voltage deviates too much from the true sine wave. The effective series resistance of the filter inductors should be made as small as possible. On the other hand, the error term provides an evaluation of system performance. One could calculate the maximum possible $\Delta v_{o}[k]$ during the design phase. Then, choose an appropriate sampling time $T_{s}$ and the filter inductance $L$ to accommodate to system requirements. Ideal voltage and current waveforms are illustrated in Fig. 2.

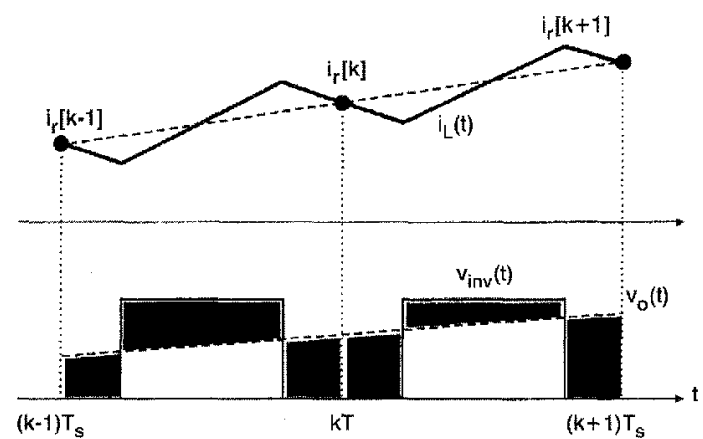

Fig. 2 Inductor voltage and current waveforms 


\subsection{Effect of a delay of one sampling period}

To smooth the inductor current waveform, the sampling frequency $f_{s}$ is usually chosen as high as possible. Unfortunately, a high sampling frequency implies a severe time delay in the controller. Refer to the control block diagram in Fig. 3. The switches and the zero-order-hold $(\mathrm{ZOH})$ represent the sample-and-hold operations. A time delay always exists from sampling the inductor current to the control signal $u[k]$ generation. It is mainly composed of the computational time required for the microprocessor and the data conversion time of $\mathrm{A} / \mathrm{D}$ converters. As sampling frequency becomes high, the delay time may extend to one full sampling period. In practice, the sampling period is usually chosen to be just long enough to complete data sampling and control signal calculations to achieve fast response current control. The time delay induces not only inaccurate results but also an unstable system.

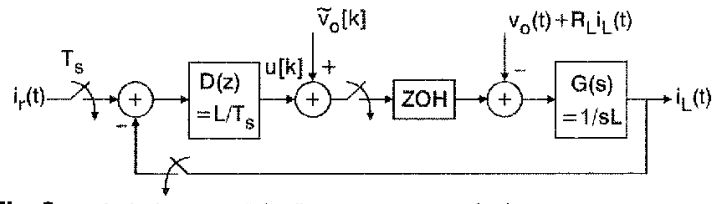

Fig.3 Block diagram of deadheat current control scheme

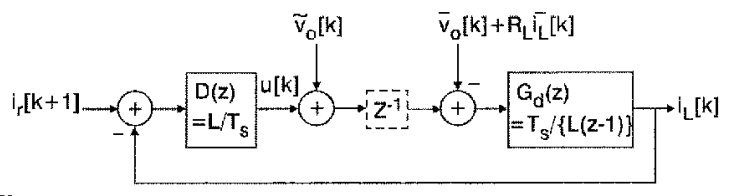

Fig. 4 Discrete equivalent of control block diagram

For simplicity, a delay of one sampling period is assumed for analysing the problem. To analyse the delay effect on $z$-plane, first redraw the discrete equivalent of the mixed control block diagram in Fig. 4. The delay of one sampling period is modelled by the $z^{-1}$ block, and the $\mathrm{ZOH}$ cquivalence [8] of the inductor transfer function is given by

$$
\begin{aligned}
G_{d}(z) & =\left(1-z^{-1}\right) \cdot \mathrm{L}\left[\frac{G(s)}{s}\right] \\
& =\left(1-z^{-1}\right) \cdot \mathrm{L}\left[\frac{1}{s^{2} L}\right] \\
& =\left(1-z^{-1}\right) \cdot \frac{z}{(z-1)^{2}} \cdot \frac{T_{s}}{L} \\
& =\frac{T_{s}}{L} \cdot \frac{1}{z-1}
\end{aligned}
$$

where $\mathbf{L}$ is the Laplace transformation operator.

The pole of the system without delay (i.e. without the $z$ block in Fig. 4) is easily calculated:

$$
1+D(z) \cdot G_{d}(z)=0
$$

which is reduced to

$$
z=0
$$

However, when the delay of one sampling period is introduced, the system is found to have two problems. First, the estimation of the mains voltage is delayed. This can be easily corrected by supposing that the mains is a sinusoidal voltage source and predicted precisely by applying eqn. 3 . On the other hand, the delayed control signal is difficult to compensate for. To find the poles of the system with the $z^{-1}$ block, the system characteristic equation is written as

$$
1+D(z) \cdot z^{-1} \cdot G_{d}(z)=0
$$

Solve it for the poles:

$$
\begin{aligned}
& z^{2}-z+1=0 \\
& z=\frac{1 \pm j \sqrt{3}}{2}
\end{aligned}
$$

Compared to the nondelayed system in Fig. 5, the poles are moved from origin to locations on the unit circle on the $z$-plane, which exhibits a pure oscillating discrete system. To further see how stability margins are affected, their frequency responses are also obtained by substituting $z=$ $e^{j 2 \pi T_{s}}$ into system loop gains with and without delay. Referring to Fig. 6 , it is found that, at one sixth of the sampling frequency $f_{s}$, the phase response of the system with a delay of one sampling period crosses over the $-180^{\circ}$ line. The interpretation is that the $\mathrm{ZOH}$ introduces a time delay of $T_{s} / 2$ on average and the sampling period contributes an additional time delay of $T_{s}$. The total $3 T_{S} / 2$ delay time adds $90^{\circ}$ phase shift to the original $90^{\circ}$-lagged phase response of the inductor transfer function exactly at frequency $f_{s} / 6$. The phase margin is thus reduced from $60^{\circ}$ of the nondelaycd system to zero.

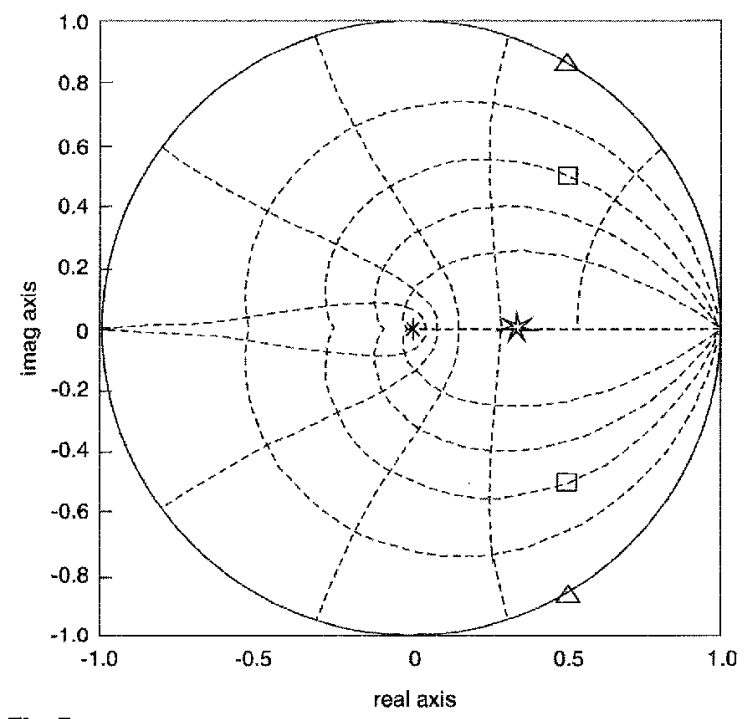

Fig.5 Locations of system poles

* nondelelyed system or with predictive current observer

$\wedge$ with one-sampling-period delay

$\sqcup$ reducing controller gain

\section{Discussion of different delay compensation methods}

\subsection{Reducing controller gain}

The design of a three-phase PWM AC-DC converter presented in [5] implies reducing controller gain to obtain a stable current control. For example, if the controller function $D(z)$ in Fig. 4 is reduced by one half to be $L /\left(2 T_{s}\right)$, the system characteristic equation (eqn. 12) changes to

$$
z^{2}-z+\frac{1}{2}=0
$$

with system poles $z=(1 \pm j) / 2$. Referring to Fig. 5 , the system is stabilised by moving poles back inside the unit circle, but at the expense of the closed-loop gain also being changed. The phase difference between reference and the output current increases. For example, it can be calculated that a phase lag of $3.6^{\circ}$ exists between $i_{L}$ an $i_{r}$ even at such a low frequency $f_{s} / 100$. 


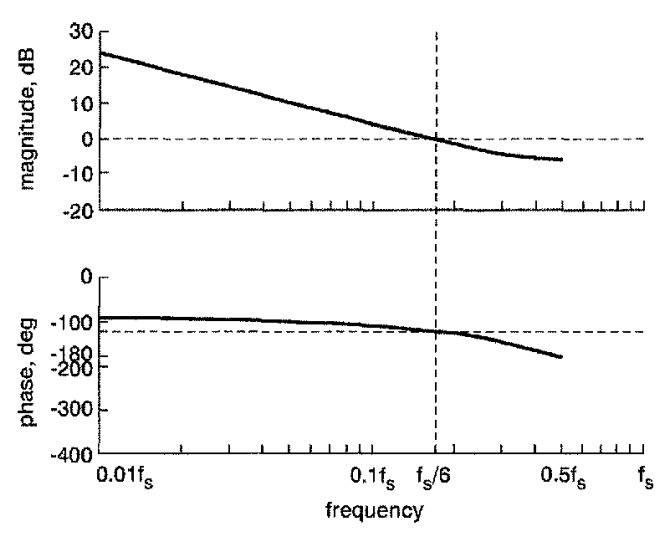

a

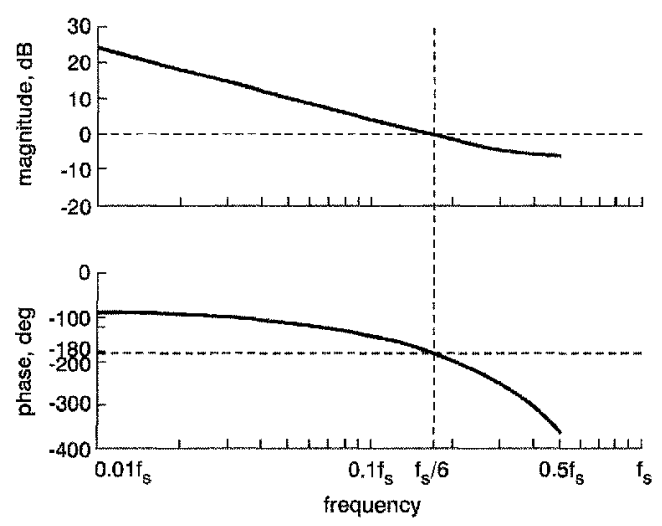

b

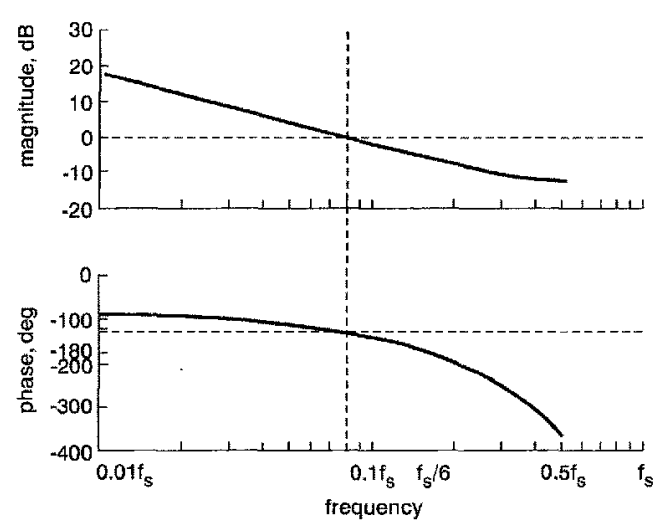

Fig. 6 Frequency response of system loop gain a Nondelayed system $c$ With reducing controller gain method

\subsection{Binomial current controller}

A binomial current controller has been invented in [11] for three-phase inverters. The control signal $u[k]$ is calculated based on historical current errors:

$$
u[k]=\frac{L}{T_{s}} \cdot \sum_{m=1}^{N} K_{m}\left(i_{r}[k+1-m]-i_{L}[k-m]\right)
$$

Because $i_{l}[k]$ does not show up in eqn. 14 when calculating $u[k]$, the calculations are completed during the $(k-1)$ th sampling interval without the delay problem. Then, the

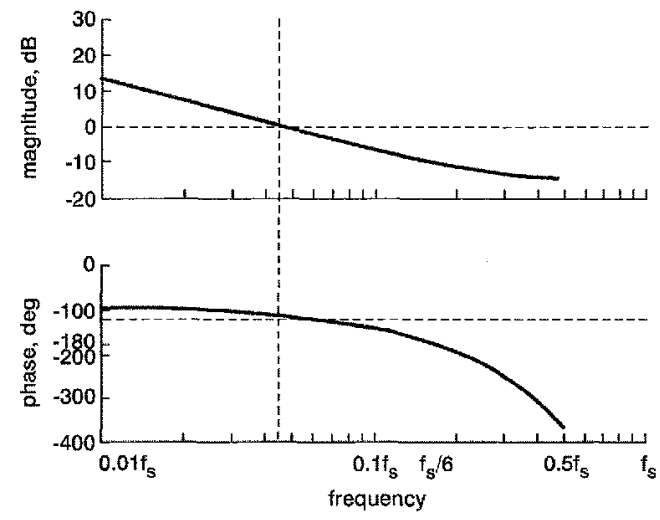

$d$

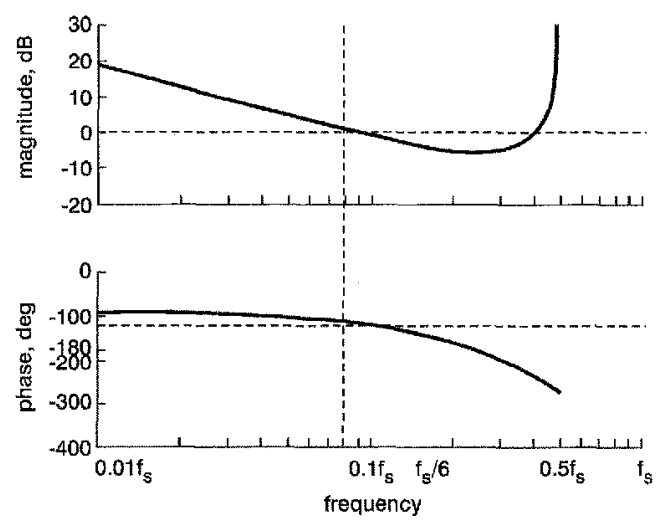

e system characteristic equation is written as

$$
z^{N+1}-z^{N}+\sum_{m=1}^{N} K_{m} \cdot z^{N-m}=0
$$

If the coefficients of the controller equation (eqn. 14) are assigned by

$$
K_{m}=(-1)^{m+1} \cdot C_{m+1}^{N+1} \cdot\left(\frac{1}{N+1}\right)^{m+1}
$$

the characteristic equation (eqn. 15) reduces to a binomial 
form,

$$
\left(z-\frac{1}{N+1}\right)^{N+1}=0
$$

with system poles at $z=1 /(N+1)$. The result implies that one can place all the poles as close to the origin on $z$-plane as possible by increasing $N$. The first-order binomial current controller is an example of the reducing gain method. Nevertheless, a large value of $N$ is required to achieve better stability margins. It means more calculations and longer computational time. A long sampling period or a low sampling frequency results. The pole locations on the $z$-plane and the frequency response of system loop gain with $N=2$ are plotted in Fig. 5 and Fig. 6, respectively, for comparison. However, it also has similar drawbacks as the reducing gain method. A more severe phase lag of $8.5^{\circ}$ is introduced between $i_{L}$ an $i_{r}$ at frequency $f_{s} / 100$.

\subsection{Predictive current observer based controller}

The predictive observer is originally used in vector control of induction motors to predict rotor flux [12]. The stator current is also predicted to avoid the computational delay in a digital controller. The observer gain can be adjusted to place system poles to be specified conjugate complex pairs in order to achieve stable control. For solar inverter applications, the gain is chosen to be unity, and the inductor current in eqn. 5 is predicted during the previous sampling interval:

$$
\hat{i}_{L}[k]=i_{L}[k-1]+\frac{T_{s}}{L} \cdot u[k-1]
$$

The prediction is reasonable since the control signal is generated to correct the current error. Replacing $i_{L}[k]$ in eqn. 5 by eqn. 18, a recursive controller equation is obtained:

$$
\begin{aligned}
u[k] & =\frac{L}{T_{s}} \cdot\left(i_{r}[k+1]-\hat{i}_{L}[k]\right) \\
& =\frac{L}{T_{s}} \cdot\left(i_{r}[k+1]-i_{L}[k-1]-\frac{T_{s}}{L} \cdot u[k-1]\right)
\end{aligned}
$$

The control signal $u[k]$ now can be calculated one sampling period ahead. Although $\tilde{v}_{0}[k]$ in eqn. 4 has also to be estimated one sampling pcriod ahead, it is calculated precisely by eqn. 3 as long as the mains is a sinusoidal voltage source. The inductor eqn. 1 is then simplified as

$$
i_{L}[k+1]=i_{L}[k]+\frac{T_{s}}{L} \cdot u[k]+\frac{T_{s}}{L} \cdot \Delta v_{o}[k]
$$

Apply the $z$-transformation to eqn. 19 and reduce it to a nonrecursive form:

$$
\begin{aligned}
U[z] & =\frac{L}{T_{s}} \cdot\left[\frac{z}{1+z^{-1}} \cdot I_{r}(z)-\frac{z^{-1}}{1+z^{-1}} \cdot I_{L}(z)\right] \\
& =\frac{L}{T_{s}\left(1+z^{-1}\right)} \cdot\left[z \cdot I_{r}(z)-z^{-1} \cdot I_{L}(z)\right]
\end{aligned}
$$

Apply the $z$-transformation to eqn. 20 again:

$$
I_{L}(z)=\frac{T_{s}}{L} \cdot \frac{1}{z-1} \cdot U(z)+\frac{T_{s}}{L} \cdot \frac{1}{z-1} \cdot \Delta V_{o}(z)
$$

and substitute eqn. 21 into eqn. 22 , the closed-loop equation is obtained:

$$
I_{L}(z)=I_{r}(z)+\frac{T_{s}}{L} \cdot \frac{z+1}{z^{2}} \cdot \Delta V_{o}(z)
$$

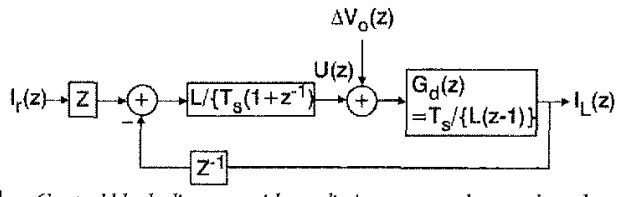

Fig.7 Control block diagram with predictive current observer based controller

If the error term on the right-hand side of eqn. 23 is neglected, a simple but precise deadbeat control results and is exactly the same as the nondelayed one. To illustrate the system stability in a similar way, the control block diagram is drawn in Fig. 7. The system characteristic equation is found to be

$$
\begin{aligned}
1+\frac{L}{T_{s}\left(1+z^{-1}\right)} \cdot G_{d}(z) \cdot z^{1} & =1+L(z) \\
& =1+\frac{1}{z^{2}-1} \\
& =0
\end{aligned}
$$

with a double pole at $z=0$. System poles are moved back to the origin on the $z$-plane. The frequency response of system loop gain is

$$
L\left(e^{j 2 \pi f T_{s}}\right)=\frac{1}{e^{j 4 \pi f T_{s}}-1}
$$

Fig. $6 e$ shows that the phase margin is recovered to $60^{\circ}$

\section{Sensitivity}

It seems that the predictive current observer based deadbeat control has the same performance as the nondelayed one. To investigate this point, the sensitivities of both systems are compared. First, the performances of the two control algorithms are both affected by the estimation error of the mains voltage and the effective series resistance of the filter inductors. Rewrite eqn. 7 of the nondelayed control as

$$
I_{L}(z)=I_{r}(z)+\frac{T_{s}}{L} \cdot \frac{1}{z} \cdot \Delta V_{o}(z)
$$

and compare it with eqn. 23 . The error responses obtained by substituting $z=e^{j 2 \pi f T_{s}}$ into the error terms of eqn. 26 and eqn. 23 are

$$
\begin{aligned}
& \left|E\left(e^{j 2 \pi f T_{s}}\right)\right|_{\text {Iont-delinyed }} \\
& =\frac{T_{s}}{L} \cdot \frac{1}{\left|e^{j 2 \pi f T_{s}}\right|} \cdot\left|\Delta V_{o}\left(e^{j 2 \pi f T_{s}}\right)\right| \\
& =\frac{T_{s}}{L} \cdot\left|\Delta V_{o}\left(e^{j 2 \pi f T_{s}^{\prime}}\right)\right| \\
& \left|E\left(e^{j 2 \pi f T_{s}}\right)\right|_{\text {predictive }} \\
& =\frac{T_{s}}{L} \cdot \frac{\left|e^{j 2 \pi f T_{s}}-1\right|}{\left|e^{j 4 \pi f T_{s}}\right|} \cdot\left|\Delta V_{o}\left(e^{j 2 \pi f T_{s}}\right)\right| \\
& =\frac{T_{s}}{L} \cdot\left|e^{j 2 \pi f T_{s}}-1\right| \cdot\left|\Delta V_{o}\left(e^{j 2 \pi f T_{s}}\right)\right|
\end{aligned}
$$

The result is shown in Fig. 8. It is found that, at low frequencics, the current error of the predictive control is twice as large as that of the nondelayed one with the same mains voltage estimation error.

Secondly, one of the shortcomings of the deadbeat control is that it is parameter-dependent. Inaccurate model parameters degrade control performance. To find their sensitivities to system parameter deviations, replace the $L / T_{s}$ term of plant model $G_{d}(s)$ by $K L / T s$, and recalculate both two closed-loop transfer functions. Neglect estimation 
error of the mains voltage. The nondelayed transfer function would be

$$
T_{1}(z)=\frac{I_{L}(z)}{I_{r}(z)}=\frac{K \frac{L}{T_{s}} z}{z+K \frac{L}{T_{s}}-1}
$$

with sensitivity to $K$

$$
\begin{aligned}
S_{K}^{T} & =\frac{K}{T_{1}} \cdot \frac{\partial T_{1}(z)}{\partial K} \\
& =\frac{z-1}{z-1+K \frac{L}{T_{s}}}
\end{aligned}
$$

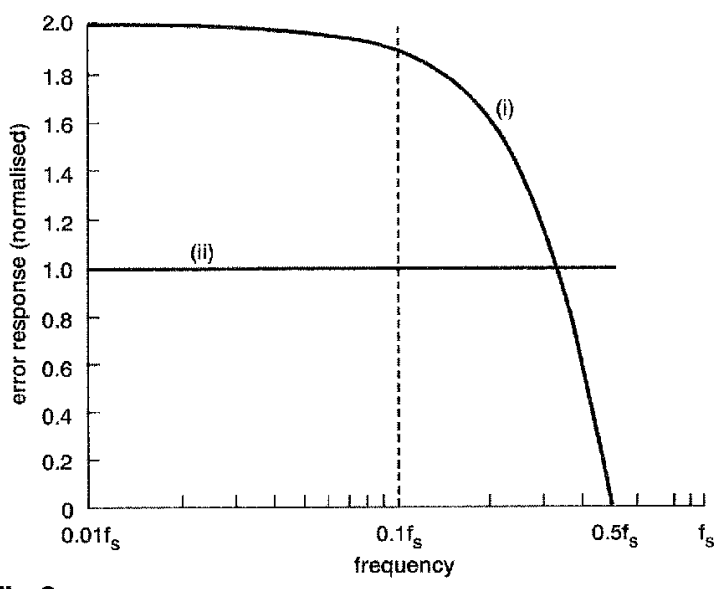

Fig.8 Error response

(i) with predictive current observer (ii) nondelayed deadbeat control
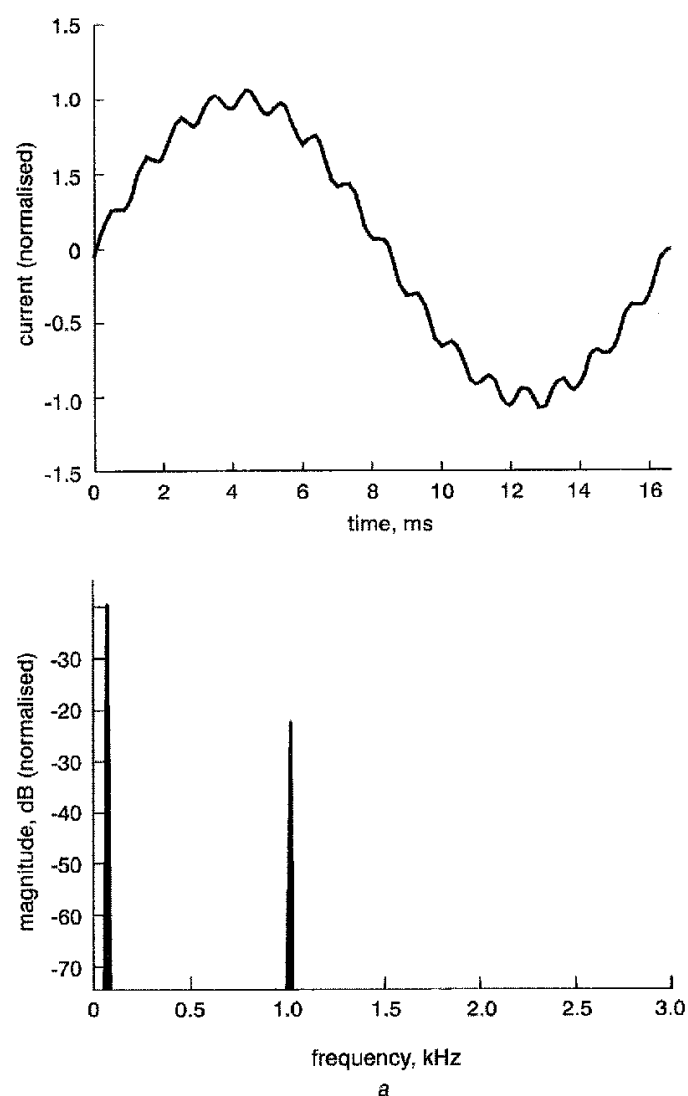

Fig.9 Computer simutations

$a$ With one-sampling-period delay
$b$ With predictive current observer based controller
The predictive transfer function becomes

$$
\begin{aligned}
T_{2}(z) & =\frac{K \frac{L}{T_{s}} z^{2}}{z^{2}+\left(K \frac{L}{T_{s}}-1\right) z} \\
& =\frac{K \frac{L}{T_{s}} z}{z+K \frac{L}{T_{s}}-1}
\end{aligned}
$$

It is the same as $T_{1}(z)$, so the sensitivity of the predictive current observer based deadbeat controller remains unchanged.

\section{Computer simulations and experimental results}

The deadbeat current control schemes with a delay of one sampling period and with the predictive current observer based controller are both simulated on MATLAB. The sampling frequency is chosen to be 100 times the mains frequency. Referring to Fig. 9, it is observed that the time delay causes high-frequency oscillation on the sinusoidal current waveform. By applying FFT to it, the oscillation frequency is found to be at one sixth of the sampling frequency, consistent with the previous discussions. The phenomenon is greatly reduced by using the predictive current observer based controller.

To further verify the analysis, a $1 \mathrm{~kW}$ solar inverter with the power circuit shown in Fig. 1 is implemented. System parameters are listed in Table 1. A 16-bit microprocessor $80196 \mathrm{MC}$ with an on-chip A/D converter is adopted as the main controller. The sampling frequency is chosen as $6 \mathrm{kHz}$ and is synchronised with the $60 \mathrm{~Hz}$ line frequency. The $167 \mu$ s sampling period is estimated so that it is just long enough for executing the control program oncc.
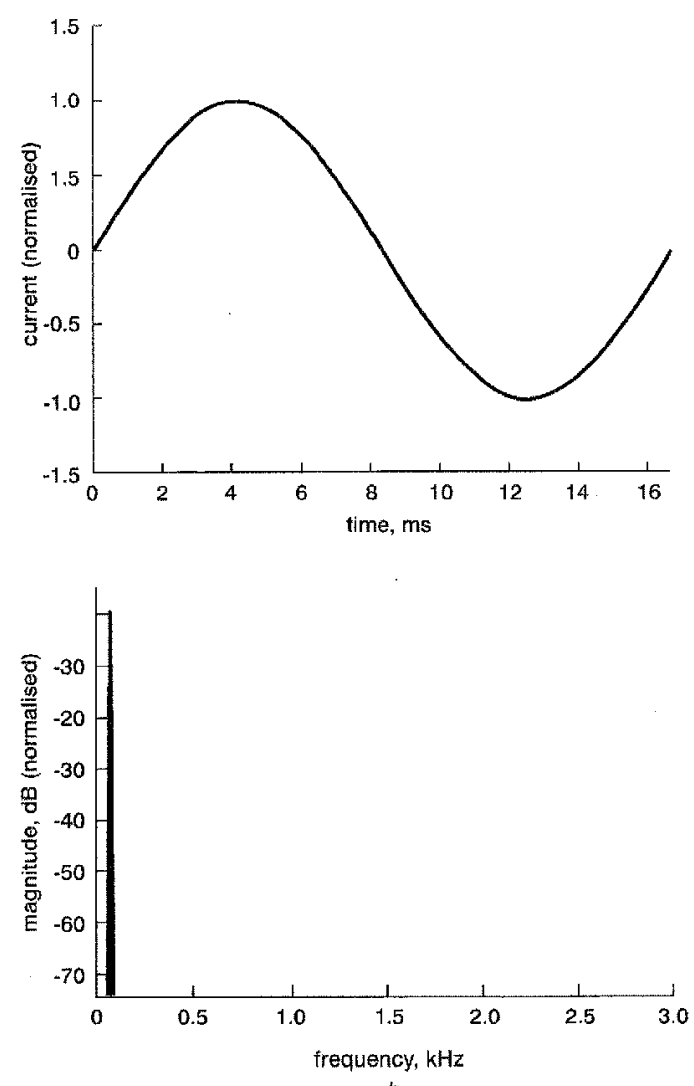

IEE Proc-Circuits Devices Syst., Vol. 148, No. 5, Octoher 2001 

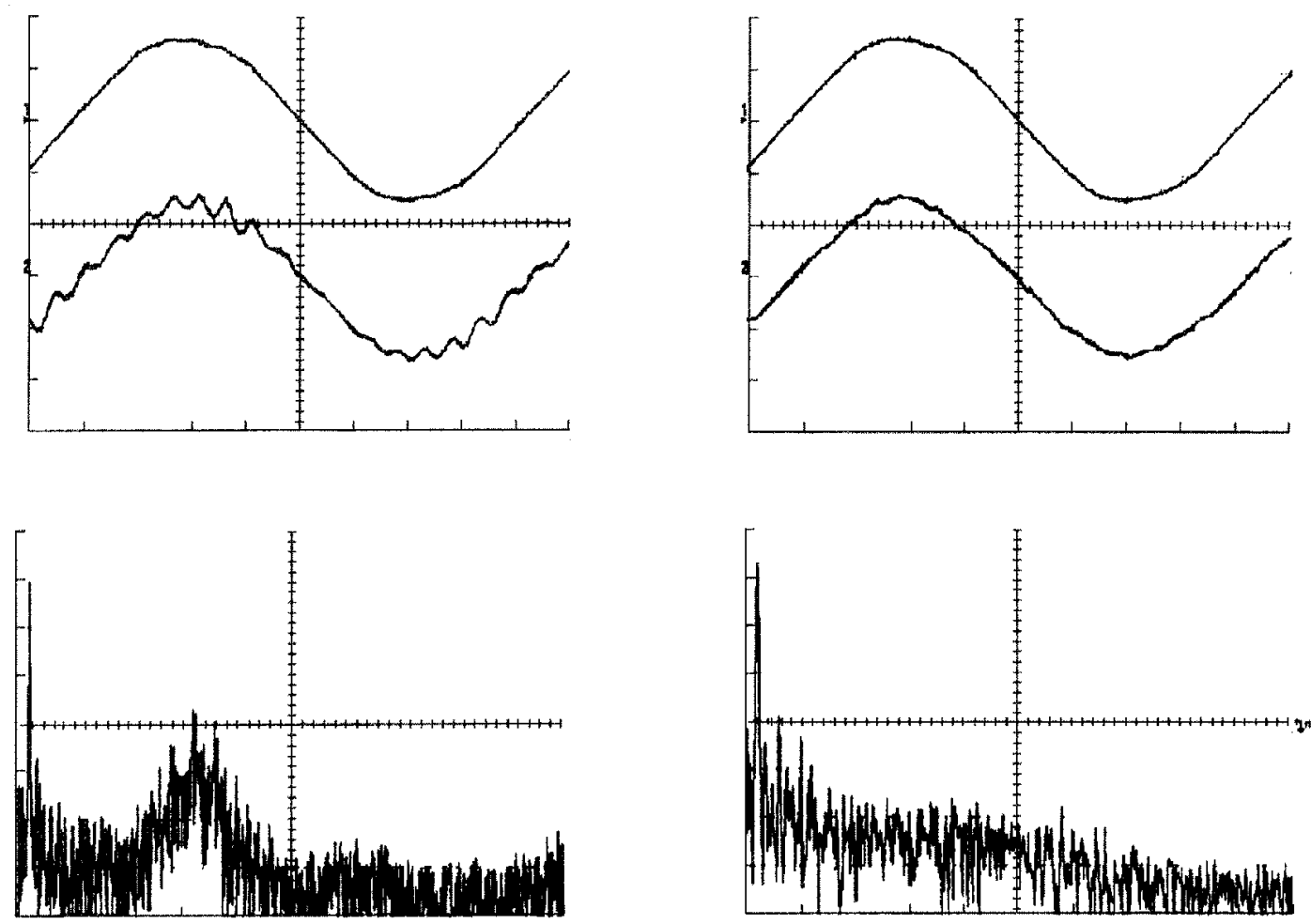

Fig.10 Experimental results

Time-domain waveforms - voltage: $100 \mathrm{~V} / \mathrm{div}$, current: $10 \mathrm{~N} / \mathrm{div}$; time: $2 \mathrm{~ms} / \mathrm{div}$

Frequency-domain waveforms - verticet: $10 \mathrm{~dB} / \mathrm{div}$, horizontal: $300 \mathrm{~Hz} / \mathrm{div}$ wilh centre frequency at $1.5 \mathrm{kHz}$

a With one-sampling-period delay

$b$ With predictive current observer bascd controllor

The complete program includes the current control opcration, the maximum power point tracking (MPPT) of solar panels, multiplexing $\mathrm{A} / \mathrm{D}$ conversions, system $\mathrm{I} / \mathrm{O}$ and monitoring, etc. Besides, the switching frequency is chosen as $18 \mathrm{kHz}$ and is also synchronised with sampling frequency to further reduce the current ripple. Fig. 10 gives the experimental results corresponding to the computer simulations. The THD values of voltage and current waveforms are provided by a Voltech PM3000A power analyser.

Table 1: Solar inverter parameters

\begin{tabular}{ll}
\hline & Solarex MSX64 unit \\
Solar panels & $P_{\max }=63 \mathrm{~W}, \mathrm{~V}_{\text {open }}=21.2 \mathrm{~V}$, \\
& $I_{\text {short }}=3.97 \mathrm{~A}$, total 32 units \\
Switches & IGBT, 600, $50 \mathrm{~A}$ \\
Microprocessor & Intel $80196 \mathrm{MC}$ \\
Input inductance & $1 \mathrm{mH}$ \\
Output inductance & $2 \mathrm{mH}$ \\
DC bus capacitance & $2820 \mu \mathrm{F}$ \\
Output capacitance & $3 \mu \mathrm{F}$ \\
DC bus voltage & $400 \mathrm{~V}$ \\
Mains voltage & $110 \mathrm{~V}, 60 \mathrm{~Hz}$ \\
Sampling frequency & $6 \mathrm{kHz}$ \\
Switching frequency & $18 \mathrm{kHz}$ \\
\hline
\end{tabular}

One thing to be indicated is that the current reference is defined as a $60 \mathrm{~Hz}$ purely sinusoidal wave in the program. It is synchronised by detecting the zero-crossing of the mains voltage. In practice, the mains voltage waveform is usually distorted with its frequency drifting all the time. So, it is neccssary to resynchronise the reference sine wave by detecting the zero-crossing of the mains voltage about every $16.7 \mathrm{~ms}$. Because of the drifting mains frequency, a true unity power factor cannot be guaranteed in this way. The distorted mains voltage waveform also induces a phase shift between its fundamental component and the reference current. However, the method is easy to implement and provides the capability of monitoring the mains frequency. Other methods may be used for improvement. For example, samples of the mains voltage can be defined as the reference current after scaling. This will be a topic for further studies.

\section{Conclusions}

Time delay always exists in a digital controlled system due to the nonzero computational time of the microprocessor and conversion time of A/D converters. When a low-speed microprocessor is used, the delay time may extend to a full sampling period, which results in not only inaccuracy but also unstable current control. For solar inverter applications, the analysis based on $z$-transformation and frequency responses of system loop gain reveals that system poles are moved outward to locations on the unit circle on $z$-plane and an oscillation occurs at one sixth of the sampling frequency because of the delay of one sampling period. Some methods have been proposed to solve this problem. It is found that the predictive current observer based controller compensates the time delay by recovering system stability margin to that of a nondelayed system while retaining accurate current control as in a nondelayed system. The only difference is that the current error increases at low frequencies. Computer simulations are 
performed, and a $1 \mathrm{~kW}$ solar inverter using a $80196 \mathrm{MC}$ microprocessor as the main controller is constructed for the experiments. Both exhibit the same results as in the theoretical analysis.

\section{References}

1 MALESANI, L., and TOMASIN, P.: 'PWM current control techniques of voltage source converters - a survey'. Proceedings of IECON, 1993, Vol. 2, pp. 670675

2 LEE, D.C., SUL, S.K., and PARK, M.H.: 'Comparison of AC current regulators for IGBT inverterr. Proceedings of IEEE Power conversion conference, 1993 , pp. 206-212

3 JEONG, S.G., and WOO, M.H.: 'DSP based active power filter with predictive current control', IEEE Trans. Ind. Electron., 1997, 44, (3), pp. $329-336$

4 WU, R., DEWAN, S.B., and SLEMON, G.R.: 'A PWM AC-to-DC converter with fixed switching frequency', IEEE Trans. Ind. Appl., $1990,26,(5)$, pp. $880-885$
5 ITOH, Y., and KAWAUCHI, S.: 'Easy digital control of three-phase PWM converter'. Proceedings of INTELEC, 1991, pp. 727-734

6 YANG, T.C.: "On computational delay in digital and adaptive controllers'. Proceedings of International conference on control, 1994, Vol, 2, pp. 906-910

7 SHIN, K.G., and CUI, X.: 'Computing time delay and its effects on real time conirol systems', IEEE Trans. Control Syst. Technol, 1990, 3, (2), pp. 218-224

8 FRANKLIN, G.F., and POWELL, J.D.: 'Digital control of dynamic systems' (Addison-Wesley, 1980)

9 RATTAN, K.S.: 'Compensation for computational delay in digital equivalent of continuous control systems', IERE Trans. Autom. Control, $1989,34,(8)$, pp. 895-899

10 OVASKA, S.J., and VAINIO, O.: 'Predietive compensation of timevarying computing delay on real-time control systems', IEEE Trans Control Syst. Technol., 1997, 5, (5), pp. 523-526

11 KUKRER, O.: 'Discrete-time current control of voltagc-fcd threcphase PWM inverters', IEEE Trans., Power Electron, 1996, 11, (2), pp. $260-269$

12 BRAHIM, L.B., and KAWAMURA, A.: 'Digital control of induction motor current with deadbeat response using predictive state observer', IEEE Tran.. Power Electron., 1992, 7, (3), pp. 551-559 